\title{
High-resolution Thin-section T2-Weighted Magnetic Resonance Imaging Sequence as a Diagnostic Aid in Hemifacial Spasm
}

\author{
Hemifasiyal Spazmda Tanısal Yardımcı Olarak Yüksek Çözünürlüklü İnce Kesitli T2
} Ağırlıklı Manyetik Rezonans Görüntüleme Sekansı

Keywords: Hemifacial, spasm, magnetic resonance imaging

Anahtar Kelimeler: Hemifasiyal, spazm, manyetik rezonans görüntüleme

Dear Editor,

A 40-year-old woman presented with sudden onset twitching of the left eyelid and facial muscles, for 1 week. She had no pain or abnormal sensation in the left half of her face. She was not a diabetic or hypertensive. Her brain magnetic resonance imaging (MRI) without contrast revealed a vascular compression of the left hemi-medulla and left 7-8 nerve complex, close to the root entry zone, by a mildly tortuous medially-deviated left vertebral artery with normal calibre (Figures 1, 2).

Hemifacial spasm (HFS) is defined as involuntary unilateral contractions of facial muscles innervated by the ipsilateral facial nerve. It starts as painless spasms of the orbicularis muscle that may progress to involving all facial muscles. Its prevalence is 9.8 per 100,000 persons with an average age of onset of 44 years (1). HFS is usually considered a disease process of the nerve root
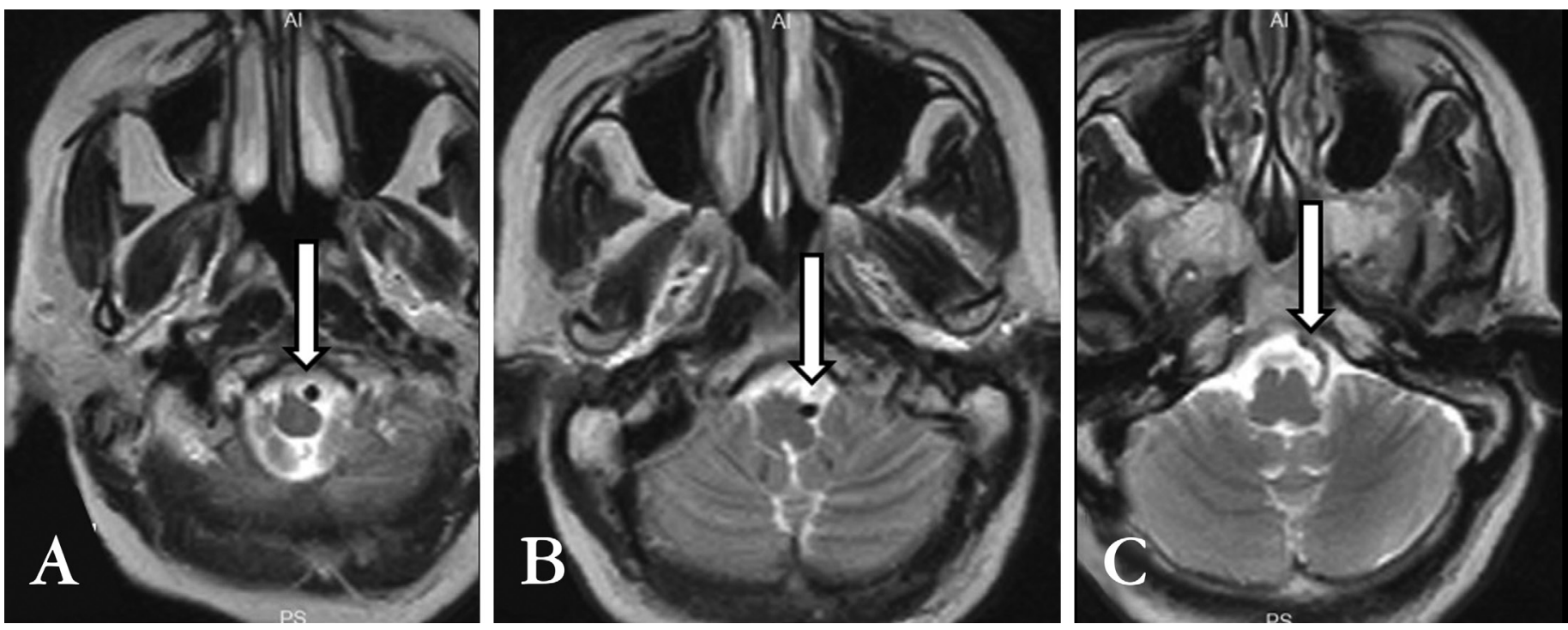

Figure 1. Axial T2-weighted magnetic resonance imaging images (A, B, C) show a mildly tortuous left vertebral artery compressing the left hemi medulla and left 7-8 nerve complex close to the root entry zone (white arrows).

Address for Correspondence/Yazışma Adresi: Venkatraman Indiran MD, Sree Balaji Medical College and Hospital, Clinic of Radiodiagnosis, Tamil Nadu, India Phone: +04422653429 E-mail: ivraman31@gmail.com ORCID ID: orcid.org/0000-0001-5296-0175

Received/Geliş Tarihi: 27.09.2017 Accepted/Kabul Tarihi: 02.10.2017

${ }^{\circ}$ Copyright 2018 by Turkish Neurological Society

Turkish Journal of Neurology published by Galenos Publishing House. 

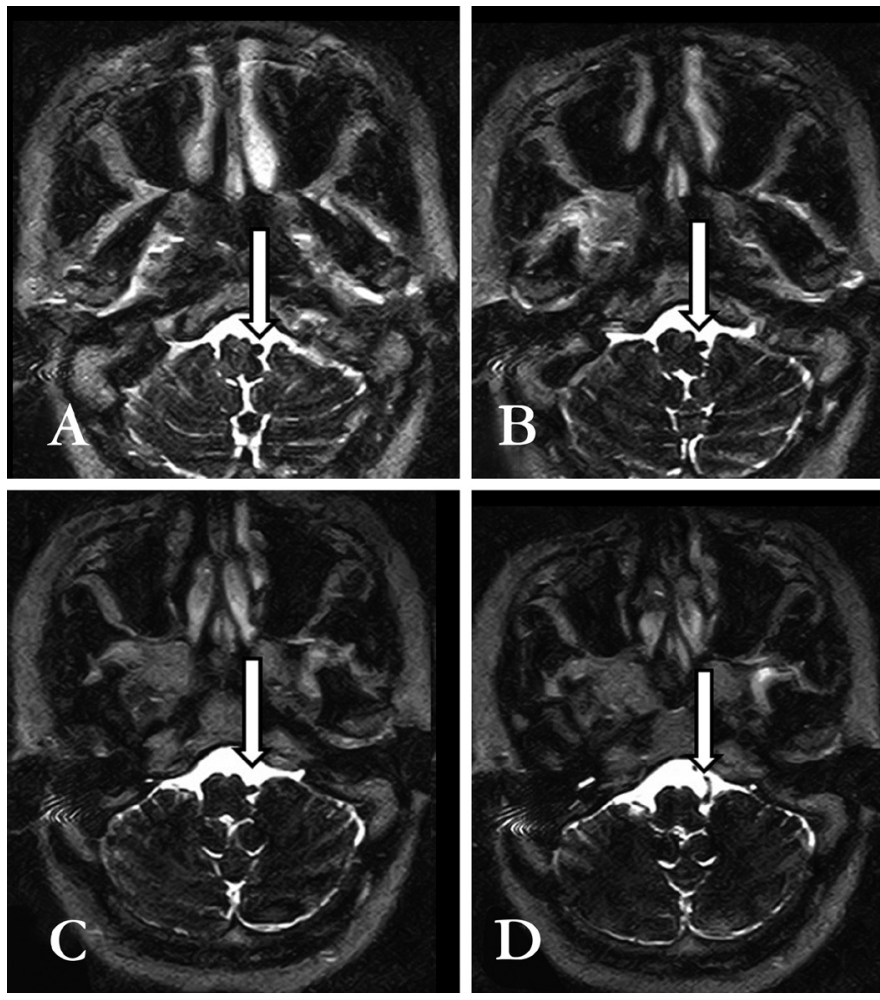

Figure 2. High-resolution thin section $\mathrm{T} 2$ magnetic resonance imaging images (A, B, C, D) shows medially deviated mildly tortuous left vertebral artery compressing over the left hemi medulla and left 7-8 nerve complex close to the root entry zone.

entry zone of the facial nerve. Primary HFS is caused by vascular compression, whereas secondary HFS is due to other causes of facial nerve damage (2). Clinical examination, electromyography, and MRI with magnetic resonance angiography (MRA) are useful for diagnosing the cause of HFS and for intraoperative planning.

Vascular compression of the facial nerve is a well-recognized cause of HFS and is caused by vascular loops or aneurysms of vertebrobasilar arterial system (anterior and posterior inferior cerebellar arteries or vertebral arteries) or due to anatomic variations in vasculature such as lateral or medial deviation of one or both vertebral arteries (2). T2-weighed MRI sequences and high-resolution fast imaging employing thin section steadystate free precession MR images can be used to display possible vascular compressions, as demonstrated in this case. Fusion MRI that combines steady-state MRI and three-dimensional timeof-flight MRA may be more useful in identifying compression at the root exit zone of the facial nerve (2). MRI is also useful in excluding other causes such as tumors and arteriovenous malformations.

Botulinum toxin injections provide low-risk symptomatic relief in $85 \%$ of patients with HFS, making it the treatment of choice for patients who refuse surgery (3). Microvascular decompression provides a curative treatment with long-term relief of symptoms by alleviating vascular compression of the facial nerve root (longterm success rates between $83 \%$ and 97\%) (4).

Neurovascular contact, which is the most common cause of HFS, is exquisitely demonstrated in MRI. Hence, it should be offered as the one-stop screening procedure in the assessment of patients with HFS.

\section{Ethics}

Informed Consent: Consent form was filled out by all participants.

Peer-review: Internally peer-reviewed.

\section{Authorships Contributions}

Concept: V.I., Design: V.I., A.A., Data Collection or Processing: V.I., A.A., Analysis or Interpretation: V.I., Literature Search: V.I., A.A., Writing: V.I., A.A.

Conflict of Interest: No conflict of interest was declared by the authors.

Financial Disclosure: The authors declared that this study received no financial support.

\section{References}

1. Nilsen B, Le KD, Dietrichs E. Prevalence of hemifacial spasm in Oslo, Norway. Neurology 2004;63:1532-1533.

2. Lu AY, Yeung JT, Gerrard JL, Michaelides EM, Sekula RF Jr, Bulsara KR. Hemifacial spasm and neurovascular compression. ScientificWorldJournal 2014;2014:349319.

3. Rosenstengel C, Matthes M, Baldauf J, Fleck S, Schroeder H. Hemifacial spasm: conservative and surgical treatment options. Dtsch Arztebl Int 2012;109:667-673.

4. Dannenbaum M, Lega BC, Suki D, Harper RL, Yoshor D. Microvascular decompression for hemifacial spasm: long-term results from 114 operations performed without neurophysiological monitoring. J Neurosurg 2008;109:410-415. 